\title{
Rapid Microdetermination of Hydroxyproline in Biomedical Samples by Flow Injection Analysis Using Cysteine as an Antioxidant
}

\author{
Kazuhide UCHIDA*1, Masako Tomoda*2, Tetsuichi Shibata*3, Shinobu IKEUCHI*4, \\ Tetsunori HaSEBE ${ }^{* 5}$, Takeshi MiWA*5, Tanekuni Nomoto*4, Kazuaki FuKuSHiMA*1, \\ Shin-ichi SAITo*2 and Seiichi INAYAMA ${ }^{\dagger * 3}$ \\ *1 Department of Anesthesiology, National Defence Medical College, Tokorozawa, Saitama 359, Japan \\ ${ }^{* 2}$ General Science Laboratory, Faculty of Science and Engineering, Sophia University, \\ Kioicho, Tokyo 102, Japan \\ ${ }^{* 3}$ Pharmaceutical Institute, School of Medicine, Keio University, Shinanomachi, Tokyo 160, Japan \\ *4 Department of Dentistry and Stomato Surgery, School of Medicine, Keio University, \\ Shinanomachi, Tokyo 160, Japan \\ *56th Department of Internal Medicine, School of Medicine, Tokai University, \\ Isehara, Kanagawa 256-11, Japan
}

\begin{abstract}
A new practical method for the rapid microdetermination of hydroxyproline (Hyp) in biomedical samples, such as tissue and urine, in the presence of a definite amount of cysteine as antioxidant was established by means of the modified KISO method using flow injection analysis. This method uses no organic solvent and requires only 9 min for each sample, which can be injected every $3 \mathrm{~min}$ (about $5 \mathrm{~h}$ is sufficient for 100 samples). A good linear relationship $(r=0.99996)$ was obtained between the concentration of Hyp $(0-80 \mu \mathrm{g} / \mathrm{ml})$ and the absorbance $(0-0.514)$. In biomedical samples (hydrolyzates of rat stomach tissue), the recoveries $(94.8-103.7 \%$ ) and the reproducibility (the mean of RSD; $\mathbf{0 . 4 8 4 \%}$ for ten kinds of rat tissues) were satisfactory. The correlation between values from this method and from the conventional KISO method was shown to be good enough $(r=0.966)$ for hydrolyzate samples $(n=95)$, when a proper amount of cysteine solution was added to both the sample and standard solutions and the concentration of the oxidant was optimized to Hyp contents.
\end{abstract}

Keywords Microdetermination, hydroxyproline, collagen, connective tissue, cysteine, antioxidant, flow injection analysis, KISO method, KISOFIA method

There has been much need for a satisfactory method for the determination of hydroxyproline (Hyp) in order to facilitate studies of collagen and elastin formation and their metabolism. In our previous study ${ }^{1,2}$, a trial involving the microdetermination of Hyp using flow injection analysis (FIA), a modification of the conventional batch method (KISO method), was investigated concerning the effect of the oxidant concentration and of a mixture of two amino acids (Pro and Gly). In order to explore the influence of amino acids and other additional substances, such as sugars, salts of fatty acids and antioxidants, and to determine the optimum conditions of the FIA system, the additional components and its concentration in the reagent solutions were reexamined, for example, with respect to the possibility of excluding harmful organic solvents and of adding antioxidants. A new practical method for the

\footnotetext{
† To whom all correspondence should be addressed.
}

rapid microdetermination of Hyp in biomedical samples was finally established by adding a definite concentration of Cys as an antioxidant to both the sample and standard solution, and also by optimizing the concentration of the oxidant. Among several thiol compounds, cysteine was found to be the most effective antioxidant, except for dithiothreitol, from a practical point of view. This FIA modification of the previous KISO method ${ }^{3}$ has now been named the KISOFIA method, the details of which are described below.

\section{Experimental}

\section{Reagents}

(1) Stock buffer solution: boric acid $(38.65 \mathrm{~g})$ and potassium chloride $(140.75 \mathrm{~g})$ were added into water $(900 \mathrm{ml})$ and adjusted to $\mathrm{pH} 8.7$ with $50 \%$ potassium hydroxide to make $1000 \mathrm{ml}$ solution. (2) Oxidant 
solution: Chloramine $\mathrm{T}(0.70 \mathrm{~g})$ was dissolved in the stock buffer soluion $(320 \mathrm{ml})$ and water $(840 \mathrm{ml})$. (3) Triton X-100 solution $(20 \mathrm{v} / \mathrm{v} \%)$ : Triton X-100 $(200 \mathrm{ml})$ was dissolved in warm water $(800 \mathrm{ml})$ and used as a surfactant. (4) Ehrlich's reagent solution: p-dimethylaminobenzaldehyde (DBA) $(102.6 \mathrm{~g})$ was dissolved in a mixture of $20 \mathrm{v} / \mathrm{v} \%$ sulfuric acid $(500 \mathrm{ml})$ and the Triton X-100 solution $(500 \mathrm{ml})$. (5) Standard Hyp stock solution $(1 \mathrm{mg} / \mathrm{ml})$ : Hyp $(0.100 \mathrm{~g})$ was dissolved in water to $100 \mathrm{ml}$. (6) Stock solution of amino acids: Gly $(0.410 \mathrm{~g})$, Pro $(0.150 \mathrm{~g})$, Ala $(0.130 \mathrm{~g})$, Glu $(0.086 \mathrm{~g})$, Arg $(0.056 \mathrm{~g})$ and Asp $(0.056 \mathrm{~g})$ were dissolved in water to $100 \mathrm{ml}$. (7) Cys stock solution $(0.5 \mathrm{M})$ : Cys $(6.056 \mathrm{~g})$ was dissolved in water to $100 \mathrm{ml}$. All the chemicals of analytical reagent grade (Wako) were used with extra pure water as the solvent.

\section{Biomedical samples}

Stomach tissues of male Wistar strain rat and back skin tissues of male Hertley strain guinea pig were isolated and stocked immediately at $-80^{\circ} \mathrm{C}$.

\section{Sample preparation}

(1) Standard Hyp solution: the Hyp stock solution $(1 \mathrm{mg} / \mathrm{ml})$ was prepared, and each aliquot of $1,2,3$ and $4 \mathrm{ml}$ was added to the Cys stock solution $(5 \mathrm{ml})$; these were then diluted with water to $50 \mathrm{ml}$ in order to make a Hyp standard solution of $20,40,60$ and $80 \mu \mathrm{g} / \mathrm{ml}$. (2) Amino acid mixture solution-1 (AAM-1): $2 \mathrm{ml}$ of the stock solution of amino acids was added to a solution containing given amounts of Hyp (described below) and the same definite amount of Cys. These mixtures were diluted with water to $50 \mathrm{ml}$. The final content of the amino acid in each AAM-1 (Table 1) corresponds to the amino acid component of human skin (Hyp; $40 \mu \mathrm{g} / \mathrm{g}$ ). ${ }^{4}$ (3) Amino acid mixture solution-2 (AAM-2): a specified amount $(1,2,3$ or $4 \mathrm{ml})$ of the stock solution of amino acids was added to each solution containing a given amount of Hyp and the same definite amount of Cys. These mixtures were diluted with water to $50 \mathrm{ml}$. The ratios of amino acids to Hyp in AAM-2 of Table 1 correspond to those of the human skin collagens ${ }^{4}$ (citrate soluble collagen). (4) Biomedical sample: wet, dried or homogenized tissue samples $(0.05-5 \mathrm{mg})$ were put into pressure-proof screw-cap vials (4 ml content) with $6 \mathrm{M}$ hydrochloric acid $(2 \mathrm{ml})$ and submitted to hydrolysis in an oil bath at $110^{\circ} \mathrm{C}$ for $20-24 \mathrm{~h}$. The hydrolyzate of the tissues was then dried up by lyophilization methods and dissolved by a definite volume of $0.01 \mathrm{M}$ Cys solution $(1-2 \mathrm{ml})$.

\section{Apparatus}

(1) Pump: a double-plunger micropump [Kyowa Seimitsu (Kyowa) KHU-W-294] was used to flow the oxidant and the Ehrlich's reagent solution together with a pressure gauge (Kyowa KOG-50L) and two air dampers (Kyowa KU-AIR)(Fig. 1). (2) Sample injector: ${ }^{5}$ a pair of six-valve systems (Kyowa, KMM-6V-2) was used for sample injection with a volume of $100 \mu$. (3) Spectrophotometer: the absorbance at $560 \mathrm{~nm}$ was measured by a double-beam spectrophotometer(JASCO UVIDEC340) with a microflow cell (JASCO FIC-361, light pass

Table 1 Concentration effects of Chloramine $\mathrm{T}$ and Cys on the color development from Hyp in water and amino acids solution

\begin{tabular}{cccccc}
\hline $\begin{array}{c}\text { Sample } \\
\text { No. }^{\mathrm{a}}\end{array}$ & $\begin{array}{c}\text { Concentration/mM } \\
\text { Chloramine T }\end{array}$ & Cys & \multicolumn{2}{c}{$\begin{array}{c}\text { Ratio of absorbance } \\
\text { difference of Hyp }\end{array}$} & $\begin{array}{c}\text { Calibration } \\
(20 \mu \mathrm{g} / \mathrm{ml})\end{array}$ \\
\hline 1 & 0.50 & 0.5 & 17.6 & -1.5 & 7.49 \\
slope curve $^{\mathrm{c}}$ & \\
\hline 2 & 0.50 & 1.0 & 0.2 & -9.7 & 7.57 \\
3 & 0.71 & 1.0 & 20.2 & 0.7 & 7.19 \\
4 & 0.71 & 2.0 & -1.0 & -9.0 & 7.35 \\
5 & 0.71 & 10.0 & -2.9 & -12.7 & 2.67 \\
6 & 0.85 & 10.0 & -1.1 & -11.7 & 3.41 \\
7 & 1.10 & 10.0 & -7.6 & -8.8 & 4.13 \\
8 & 1.40 & 10.0 & -1.5 & -9.6 & 5.09 \\
9 & 1.80 & 10.0 & -4.7 & -6.4 & 6.02 \\
10 & 2.10 & 10.0 & -7.7 & 2.7 & 6.14 \\
11 & 8.90 & 50.0 & 12.5 & -2.2 & 4.23 \\
12 & 7.80 & 50.0 & -7.3 & 2.4 & 4.00 \\
13 & 2.10 & 30.0 & 6.4 & -0.8 & 2.51 \\
14 & 4.30 & 30.0 & 2.6 & 0.0 & 4.60 \\
15 & 6.40 & 30.0 & -13.5 & -8.1 & 5.45 \\
16 & 8.50 & 30.0 & 9.3 & -2.9 & 4.86 \\
17 & 2.10 & 10.0 & -1.2 & -4.8 & 6.21 \\
18 & 2.50 & 10.0 & 1.3 & -2.5 & 6.49 \\
\hline
\end{tabular}

a. No. 1-No. 16: Hyp in AAM-1, No. 17 and No. 18: Hyp in AAM-2. b. [(absorbance from Hyp in amino acids solution)-(absorbance from Hyp in water)]/(absorbance from Hyp in water) $\times 100$. c. Concentration of Hyp $(\mu \mathrm{g} / \mathrm{ml}) /$ absorbance. 


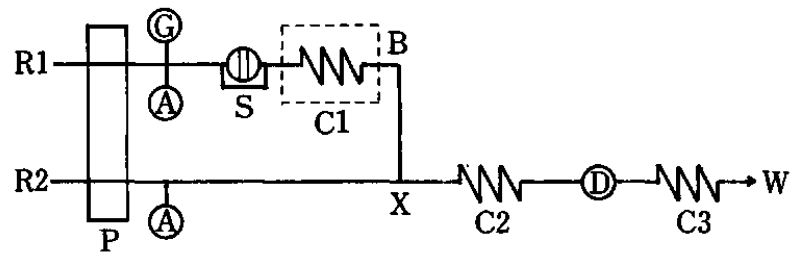

Fig. I Flow diagram of a microdetermination of Hyp by use of flow injection analysis (FIA). R1, Buffer and oxidant solution; R2, Ehrlich's reagent solution; $P$, plunger pump; G, pressure gauge; $A$, air damper; $S$, sample injector; $B$, oil bath; $\mathrm{Cl}$, mixing coil (1 mm i.d. $\times 24 \mathrm{~m})$; $\mathrm{C} 2$, reaction coil $(1 \mathrm{~mm}$ i.d. $\times 10 \mathrm{~m})$; C3, back pressure coil $(0.5 \mathrm{~mm}$ i.d. $\times 6 \mathrm{~m}) ; \mathrm{D}$, detector: (1), spectrophotometer, $\lambda=560 \mathrm{~nm}$; (2), flow cell, cell volume $20 \mu \mathrm{l}$, light pass $10 \mathrm{~mm}$; W, waste; flow rate (both $\mathrm{R}($ and $\mathrm{R} 2$ ), $2.8 \mathrm{ml} / \mathrm{min}$.

$10 \mathrm{~mm}$, volume $20 \mu \mathrm{l}$ ). (4) Recorder: a recorder (Riken Denshi SP-G12) was equipped to record the absorbance of samples.

\section{Procedure}

A flow diagram of the FIA system under optimum conditions is shown in Fig. 1. Teflon tubing ( $1 \mathrm{~mm}$ i.d.) was used as the flow lines at $2.8 \mathrm{ml} / \mathrm{min}$ of flow rates for both the solutions of R1 and R2 mentioned below. The sample solution of standard and/or hydrolyzate of tissues was injected about $0.4 \mathrm{ml}[100 \mu l$ of the sample reservoir (S) and $300 \mu$ lover flow] using the disposable syringe $(1 \mathrm{ml})$ without a needle into a current of the oxidant solution (R1). A small and disposable filter for sterilization (e.g. Millipore SJHV L04NS, pore size $0.45 \mu \mathrm{m}$, dead volume $10 \mu \mathrm{l}$ ) was applied in order to eliminate any insoluble particles, such as humin in the sample solution at or before injection. This sample solution was oxidized and decarboxylated in a mixing coil (C1) in an oil bath (B) at $100^{\circ} \mathrm{C}$ to form pyrrole, which was then mixed with Ehrlich's reagent solution $(\mathrm{R} 2)$ in a volume ratio of $1: 1$ at point $(\mathrm{X})$ in order to produce a chromogenic compound in the reaction coil (C2). The color product was passed through the flow cell in the spectrophotometer in a continuous stream; the absorbance at $560 \mathrm{~nm}$ was proportional to the concentration of Hyp in the stream.

A back-pressure coil (C3, $0.5 \mathrm{~mm}$ i.d.) was set just after the spectrophotometer in the FIA system in order to prevent any bubble formation. Various conditions were explored at the following factors in order to obtain the optimum condition: i) the concentration of Triton $\mathrm{X}-100$ in $\mathrm{R} 2$, ii) the lengths of $\mathrm{C} 1$ and $\mathrm{C} 2$, and iii) the hyperchromic effect of some extrinsic amino acids other than Hyp introduced in the sample for color development.

There were some differences in the slopes in the calibration curves of a standard Hyp solution when compared with those in water alone, in a mixture of amino acids solution artificially mixed and in hydrolyzates of tissures. The concentration of Chloramin $T$ in
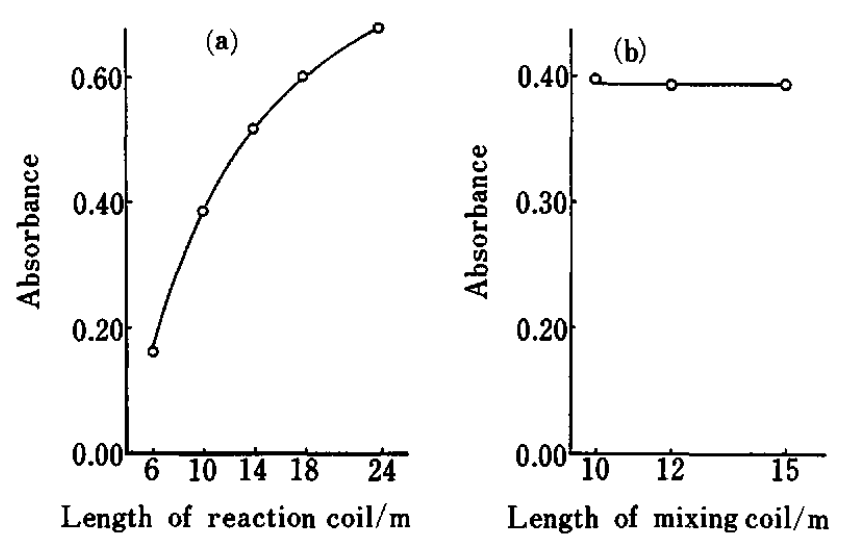

Fig. 2 (a) Optimizing length of the reaction coil. Hyp, $60 \mu \mathrm{g} /$ $\mathrm{ml}$; flow rate, $2.8 \mathrm{ml} / \mathrm{min}$. (b) Optimizing length of the mixing coil. Hyp, $60 \mu \mathrm{g} / \mathrm{ml}$; flow rate, $2.8 \mathrm{ml} / \mathrm{min}$.

$\mathrm{R} 1$ and of Cys in a sample solution was changed in the range from 0.50 to $8.90 \mathrm{mM}(0.141-2.500 \mathrm{~g} / 1)$ and from 0.50 to $50 \mathrm{mM}$, respectively. The concentration of Hyp in the hydrolyzate of stomach tissue was determined both by the batch-type KISO method ${ }^{3}$ for the conventional microquantitation of Hyp and by this flow-type KISOFIA method for a new convenient and rapid microdetermination of Hyp. The recovery rates were obtained at the spiking 7.17 or $21.5 \mu \mathrm{g}$ of Hyp into the hydrolyzate of back skin samples containing Hyp in the range from 8.20 to $26.3 \mathrm{mg} / \mathrm{ml}$ in the presence of Cys as a color stabilizing agent. The reproducibility was examined using the same hydrolyzate sample $(n=3)$.

\section{Results and Discussion}

\section{Increasing concentration of Triton $X-100$}

Ethylene glycol monomethyl ether (methyl' cellosolve) has been required as a solvent for dissolving DBA because of its sparing solubility in water. ${ }^{1,2}$ One use of organic solvents for the extraction of pyrrole or for a stabilizing agent, such as toluene in the KISO method ${ }^{3}$ or methyl cellosolve 6,7 in its FIA modification ${ }^{1,2}$ may be inadequate for targeting clean analyses. Ten percent $(\mathrm{v} / \mathrm{v})$ of a Triton X-100 solution was applied to solve DBA. Organic solvents such as ethanol, methyl cellosolve and toluene 8,9 were neglected from all of the solutions used in this method.

\section{The optimum length of the reaction coil ( $\mathrm{Cl}$ )}

The longer the length used, the higher was the absorbance obtained in this system [Fig. 2 (a)], while the half width of the peak became somewhat wider. The increasing absorbance should be ascribed to an acceleration of both oxidation and decarboxylation, which brings about a stabilization of color development in a long mixing coil. A reaction coil of $24 \mathrm{~m}$ long was practically best in consideration of the intensity and the 
(a)

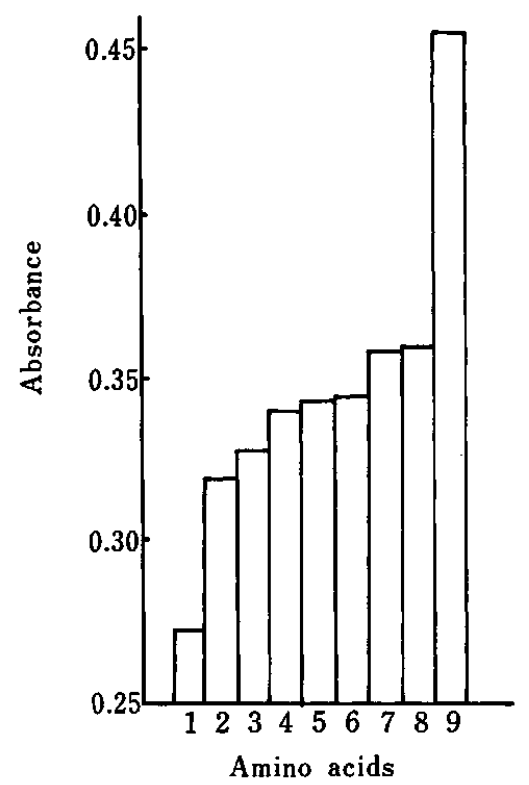

(b)

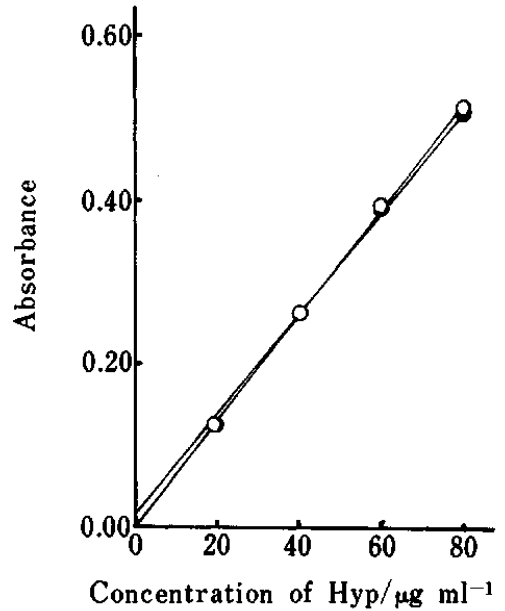

Fig. 3 (a) Antioxidative hyperchromic effect of amino acids. 1, Hyp only; 2, Hyp with Ala; 3, Hyp with Gly; 4, Hyp with Glu; 5, Hyp with Arg; 6, Hyp with Asp; 7, Hyp with Ser; 8, Hyp with Pro; 9, Hyp with Cys. Each concentration is $0.5 \mathrm{mM}$ except $0.25 \mathrm{mM}$ for No. 6. (b) Effect of Cys on absorbance. $O$, Hyp standard solution with Cys $(10 \mathrm{mM}) ; 0$, Hyp in amino acids solution (AAM-2) with Cys (10 mM).

peak shape.

The optimum length of the mixing coil (C2)

A change in the absorbance level caused by the coil length (in the range from 10 to $15 \mathrm{~m}$ ) was not found [Fig. 2(b)]. A slight drift of the baseline occurred when using an $8 \mathrm{~m}$ long coil, due to incomplete mixing of R1 and R2. An optimum ten meter long of reaction coil was applied to this system in consideration of the stability of the baseline, sampling rate and the sample dispersion.

\section{The hyperchromic effect of the amino acids}

The effect of amino acids and the concentration of their solutions to the Hyp determination are shown in Fig. 3(a). In our previous papers ${ }^{1,2}$ the differences ${ }^{10}$ of the absorbances of the pigment derived from Hyp between in water and in hydrolyzate or in a solution of amino acids could not be explained at the same Hyp content. Since there is no color development from all amino acids including tryptophane and tyrosine, other than Hyp in this system, amino acids should act as a hyperchromic agent during the oxidation process. It should be explained that a large excess of the oxidant causes an overoxidation of intermediates from Hyp to pyrrole if there are no amino acids present. When excess oxidant was consumed in the coexistence of amino acids as an antioxidant, the absorbances of the pigment derived from Hyp in the amino acids solution were higher than that from Hyp alone in water. If biomedical samples, such as hydrolyzate of tissues, were determined using the calibration curve of a standard aqueous Hyp solution, the data should involve a grave error because of the hyperchromic effect of the amino acids mentioned above. This effect seems to be ascribed to prevent the suppression of the chromophore formation with the excess oxidant ${ }^{11-13}$ and to protect the labile pyrrole-like intermediates from Chloramine T. In the case of Hyp determination in urine, excess Ala stabilizes the oxidation condition ${ }^{13}$ and prevents interferences from substances in urine. ${ }^{12}$ Insufficient amounts of the oxidant will result in an incomplete oxidation of Hyp; however, its excessive amount also results in overoxidation. ${ }^{11}$ A definite quantity of Cys, which is practically most effective (as mentioned above) among the hyperchromic effect of amino acids [Fig. 3(a)], should be added to both the standard Hyp solution and the AAM solution or biomedical samples (hydrolyzates of tissue or urine), described above. The concentration of Chloramine $T$ in the reaction coil should be balanced with that of Cys in both standard samples and the AAM solutions, as shown in Table 1 .

(1) AAM-1: a definite content of the amino acid mixture analogous to human skin was added to a series of Hyp solutions (No. 1-No. 16). (2) AAM-2: the other amino acid mixture analogous to human skin collagen was added to the other series of Hyp solution (No. 17 and No. 18). No 10 is the best among No. 1 to 


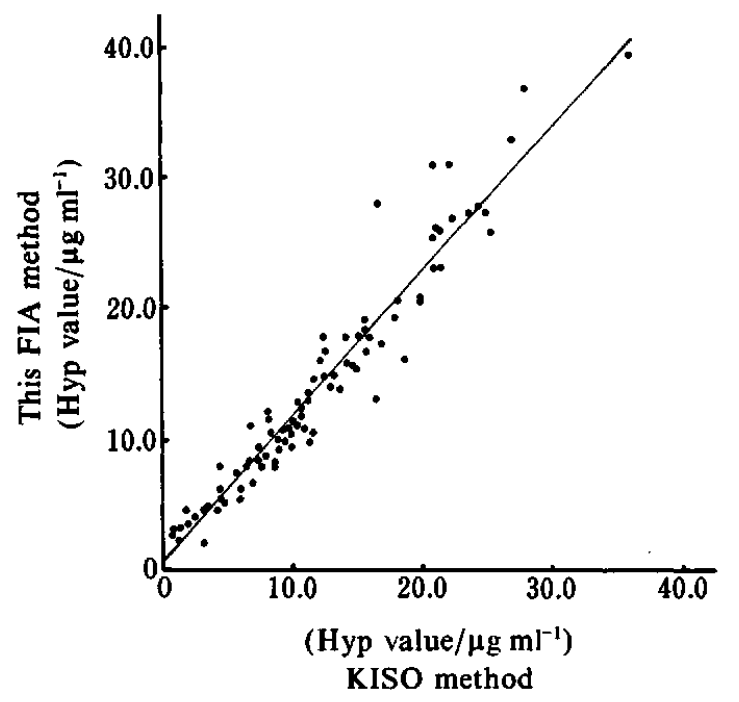

Fig. 4 Correlation of Hyp values between KISO method ${ }^{3}$ and KISOFIA method using hydrolyzate of stomach tissues. $Y=1.11 X+0.593(r=0.966, n=95)$.

Table 2 Recovery of Hyp added to the hydrolyzate of back skin tissues

\begin{tabular}{cccc}
\hline $\begin{array}{c}\text { Sample } \\
\text { No. }\end{array}$ & $\begin{array}{c}\text { Added Hyp/ } \\
\mu \mathrm{g} \mathrm{m}^{-1}\end{array}$ & $\begin{array}{c}\text { Found/ } \\
\mu \mathrm{g} \mathrm{ml}^{-1}\end{array}$ & $\begin{array}{c}\text { Recovery, } \\
\%\end{array}$ \\
\hline 1 & 0 & 8.20 & - \\
& 7.17 & 15.1 & 96.2 \\
2 & 21.5 & 30.5 & 103.7 \\
& 0 & 9.63 & - \\
3 & 7.17 & 16.6 & 97.2 \\
& 21.5 & 30.7 & 98.1 \\
4 & 0 & 10.6 & - \\
& 7.17 & 17.5 & 96.2 \\
& 0 & 16.7 & - \\
5 & 7.17 & 24.1 & 103.2 \\
& 21.5 & 38.6 & 101.9 \\
& 0 & 26.3 & - \\
6 & 7.17 & 33.1 & 94.8 \\
& 21.5 & 46.7 & 94.9 \\
& 0 & 22.7 & - \\
& 7.17 & 29.5 & 94.8 \\
& 21.5 & 43.6 & 97.2 \\
\hline
\end{tabular}

Mean of Hyp recovery rates for six samples.

1. $97.1 \pm 2.9 \%$ (mean $\pm \mathrm{SD}, n=6)$ for $7.17 \mu \mathrm{g} / \mathrm{ml}$.

2. $99.0 \pm 2.9 \%$ (mean $\pm S D, n=6$ ) for $21.5 \mu \mathrm{g} / \mathrm{ml}$.

No. 16 by referring to both the ratio of absorbance ratio in the hyperchromic effect and the slope of the calibration curve. Each absorbance in the AAM-1 and AAM-2 was compared with that of Hyp without amino acids in No. 17. Upon increasing the concentration of the oxidant to be $2.5 \mathrm{mM}(0.700 \mathrm{~g} / \mathrm{l})$, the calibration curves became stabilized; the straight line for the standard sample agreed with that for the AAM solutions under the concenttration of Cys at $10 \mathrm{mM}$ [Fig. 3(b)].
Table 3 Reproducibility of Hyp determination in the hydrolyzates of back skin tissues

\begin{tabular}{ccc}
\hline $\begin{array}{c}\text { Sample } \\
\text { No. }\end{array}$ & $\begin{array}{c}\text { Concentration/ } \\
\mu \mathrm{g} \mathrm{m}^{-1}\end{array}$ & $\begin{array}{c}\text { RSD }(n=3), \\
\%\end{array}$ \\
\hline 1 & 53.3 & 0.948 \\
2 & 44.0 & 0.418 \\
3 & 41.0 & 0.506 \\
4 & 51.9 & 0.720 \\
5 & 50.9 & 0.392 \\
6 & 72.8 & 0.267 \\
7 & 46.1 & 0.760 \\
8 & 44.0 & 0.363 \\
9 & 36.2 & 0.307 \\
10 & 46.8 & 0.156 \\
\hline
\end{tabular}

Finally, the concentration of Chloramin $T$ as the oxidant and Cys as the stabilizer for the color development was directed to be 2.5 and $10 \mathrm{mM}$, respectively. Under this condition of the aforementioned practical KISOFIA method, one can rapidly estimate a microquantity of the Hyp content in biomedical samples when compared to the previous FIA method ${ }^{1,2}$ and KISO method $^{3}$ as follows.

\section{Correlation between values from KISO method and KISOFIA method}

The correlation between the values from the KISO method $^{3}$ as a conventional batch method and from this KISIOFIA method as a continuous flow method (Fig. 4). A good linear relationship ( $r=0.966, n=95)$ was observed between the two kinds of values measured in the biomedical samples (the hydrolyzate of stomach and back skin tissues).

\section{Recovery test and reproducibility}

Recovery tests were performed using biomedical samples $(8.20-26.3 \mu \mathrm{g} / \mathrm{ml}, n=6)$; the results are shown in Table 2. Good recoveries (\%) were obtained from two series of samples of hydrolyzate added with a definite quantity of Hyp: $97.1 \pm 2.0 \%$ for $7.17 \mu \mathrm{g} / \mathrm{ml}$ Hyp and $99.0 \pm 2.9 \%$ for $21.5 \mu \mathrm{g} / \mathrm{ml}$ Hyp, mean \pm SD. The result of reproducibilities was good enough to determine the concentration of Hyp in the biomedical samples shown in Table 3 . However, if an excess amount of tissue samples was hydrolyzed with $6 \mathrm{M}$ hydrochloric acid in a vial, some insoluble particles (humin) appeared, which should decrease the accuracy of the assay. A segment-type flow method using the autoanalyzer was applied to determine Hyp in biomedical samples. ${ }^{14,15}$ However, Higashi et al. ${ }^{15}$ mentioned several problems: it is necessary to remove color substances by a pretreatment; a little carry-over still occurred; and the linear range of the calibration curve is narrow $(0-20 \mu \mathrm{g} / \mathrm{ml})$. Hyp in meat was determined using the FIA by Moeller $e t$ al. ${ }^{16}$, the method of which is similar to our previous on $e^{1,2}$ in terms of the basic reaction and detection system. However, the com- 
ponent of the solutions, especially the buffer solution system, is entirely different from ours, and the decarboxylation process in their flow system was not clearly described. In addition, the extent of interference with the endogenous materials derived from biological matrix still remains unclear, requiring further studies.

The present method has several advantages, as follows: first, a linear calibration curve was easily obtained in the range from 0 to $80 \mu \mathrm{g} / \mathrm{ml}$ and for a level less than $1 \mu \mathrm{g} / \mathrm{ml}$ of $\mathrm{Hyp}$ content. Second, this KISOFIA method system uses no organic solvent at all. Third, since the sample solution can be injected every $3 \mathrm{~min}$, the time required to assay a set of 100 samples is within $5 \mathrm{~h}$. During recent years, several procedures using high performance liquid chromatography (HPLC) have been proposed in this field. ${ }^{17}$ However, since the HPLC method requires more than $20 \mathrm{~min}$ for one sample to determine the Hyp content together with other amino acids, this method is not satisfactory regarding the increasing needs for the rapid microdetermination of Hyp alone in collagen and elastin studies. Consequently, our KISOFIA method is apparently convenient in practice both for clinicians and engineers who need to treat a large number of samples.

A new practical method for the microdetermination of Hyp in biomedical samples, such as hydrolyzate of tissues, was established by adding Cys of a definite concentration to both the sample and the standard solution, and by optimizing the concentration of Chloramin T. The present modification enables us to obtain excellent accuracy in comparison with the previous FIA method. ${ }^{1,2}$ The results obtained by this method and by the conventional KISO method ${ }^{3}$ showed good agreement with samples for various biomedical studies. Finally, this method should evidently be useful for many biomedical and clinical research programs in addition to the above two examples.

\section{References}

1. K. Uchida, T. Shibata, M. Tomoda, S. Saito and S. Inayama, Chem. Pharm. Bull., 34, 2649 (1986).

2. K. Uchida, T. Shibata, M. Tomoda, K. Fukushima, S. Saito and S. Inayama, J. Flow Inject. Anal., 5, 111 (1988).

3. S. Inayam, T. Shibata, J. Ohtsuki and S. Saito, Keio J. Med., 27, 43 (1978) [cf, R. A. Berg, Methods Enzymol., 82, 379 (1983)].

4. R. Fleishmajer and L. Fishman, Nature [London], 205, 264 (1965).

5. K. Uchida, M. Tomoda and S. Saito, J. Flow Inject. Anal., 3, 18 (1986).

6. M. Ikeda and H. Ohtsuji, Toxicol. Appl. Pharmacol., 20, 30 (1971).

7. M. Ogata, Jpn. J. Ind. Health, 23, 3 (1981).

8. H. W. Werner, J. L. Michell, J. W. Miller and W. F. vin Oettingen, J. Ind. Hyg. Tox., 25, 157 (1943).

9. K. Nagano, E. Nakayama, H. Oobayashi, T. Nishizawa, H. Okuda and K. Yamazaki, Environ. Health Perspec., 57, 75 (1984).

10. J. F. Woessner, Jr., Arch. Biochem. Biophys., 93, 440 (1961).

11. K. Juva and D. J. Prockop, Anal. Biochem., 15, 77 (1966).

12. D. J. Prockop and S. Udenfriend, Anal. Biochem., 1, 228 (1960).

13. K. I. Kivirikko, Int. Rev. Conn. Tissue Res., 5, 93 (1970).

14. R. A. Grant, J. Clin. Path., 17, 685 (1964).

15. E. Higashi, F. Sashikuma, S. Itai and H. Muranaka, Rinshokensa, 29, 1838 (1985).

16. J. Moeller and A. Sjodin, Fresenius' Z. Anal. Chem., 329, 732 (1987).

17. a) A. D. Jones, A. C. Homan, D. J. Favell and C. H. S. Hitchok, J. Chromatogr., 353, 153 (1986); b) K. Yaegaki, J. Tonzetich and A. S. K. Ng, ibid., 356, 163 (1986); c) J. Macek and M. Adam, ibid., 374, 125 (1986); d) C-P. Pang, K-C. Ho, M. G. Jones and C-K. Cheung, ibid., 386, 309 (1987); e) M. J. Dunphy, M. V. Bhide and D. J. Smith, ibid., 420, 394 (1987); f) V. Monboisse, J. C. Monboisse, J. P. Borel and A. Randoux, Anal. Biochem., 176, 395 (1989). 